\title{
NOVEL ENE- REACTIONS OF TETRACYANOETHYLENE WITH STEROIDAL DIENES
}

Anne M. Lautzenheiser and P. W. Lequesne*

Department of Chemistry, University of Michigan, Ann Arbor, Michigan 48104 U.S.A.

(Received in USA 2 0ctober 1968; received in UK for publication 8 December 1968)

Recently-described work ${ }^{l}$ on the ene-reaction between acrylonitrile and crgostcryl acctatc to give the adducts (I-III) leads us to report our investigation of some unusual reactions of tetracyanoethylene with three steroidal cisoid dienes. Tetracyanoethylene reacted rapidly with ergosteryl acetate in benzene solution to give a $1: 1$ adduct, $\mathrm{C}_{36} \mathrm{H}_{46^{\mathrm{N}} 4^{\mathrm{O}} 2^{2}}$ ** m.p. $135^{\circ},[\alpha]_{\mathrm{D}}^{25}-170^{\circ}$ in $65 \%$ yield. We suggest the structure (IV) for this compound. The adduct was extremely labile, readily decomposing with.loss of hydrogen cyanide to give intractable colored products under acidic or basic conditions or in protic solvents. The lability of the compound suggested that an ene-addition product rather than a Diels-Alder adduct had been formed (cf. ref. 1 and papers cited therein), and detailed support for structure (IV) was given by the highly characteristic spectra of the compound. The u.v. spectrum $\left[\lambda_{\max }^{\text {cyclohexane }}\right.$ $213 \mathrm{~m} \mu(\varepsilon 8080)$ ] indicated a $\Delta^{5,8(14)}$ diene system. ${ }^{1,2}$ In the n.m.r. spectrum*** the three vinyl protons at $\mathrm{C}-6, \mathrm{C}-22$, and $\mathrm{C}-23$ gave a multiplet signal at $\tau 4.80-4.92$ [ $\mathrm{cf}$. (I), C-6H at $\tau 4.58, \mathrm{C}-22 \mathrm{H}$ and $\mathrm{C}-23 \mathrm{H}$ at $\tau 4.77$ ]. ${ }^{\mathrm{I}}$ At $\tau 5.43$ the spectrum of IV showed a sharp one-proton singlet, superimposed on a broad one-proton multiplet assigned to the $\mathrm{C}-3$ proton. The singlet is ascribed to the isolated $2^{\prime}$-proton. A doublet at $\tau 6.42(\mathrm{~J}=4 \mathrm{c} . / \mathrm{sec}$.) was assigned to the C-7 allylic proton. This coupling constant indicates that the $\mathrm{C}-7$ proton is quasi-axial with respect to the C-6 vinyl proton and thus that the tetracyanoethyl side-chain is $7 \alpha-$, corresponding to the situation in $(\mathrm{I}-1 \mathrm{I} I) .{ }^{1} \mathrm{~A}$

\footnotetext{
*To whom inquiries should be addressed.

* All new compounds described gave satisfactory elemental analyses. $* * * N . m . r$. spectra were taken in $\mathrm{CDCl}_{3}$ solution.
} 


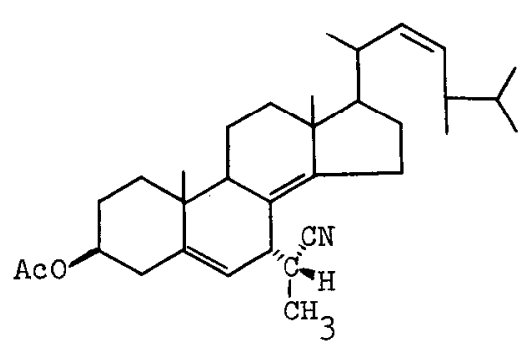

(I)

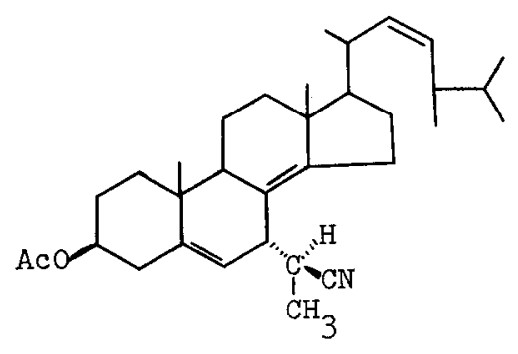

(II)<smiles>CCC(C)/C=C\C(C)C1CCC2C3=C(CCC21C)C1(C)CCC(OC(C)=O)CC1=C[C@@H]3[C@H](C)[AlH2]</smiles>

(III)

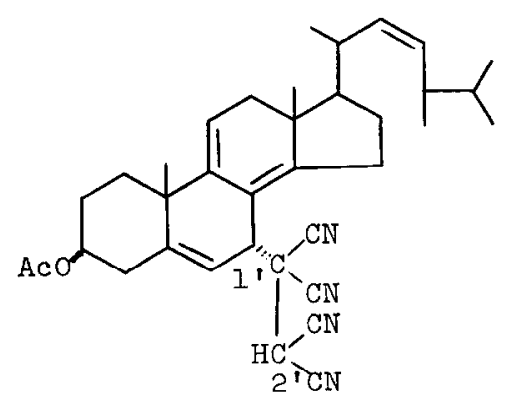

(V)

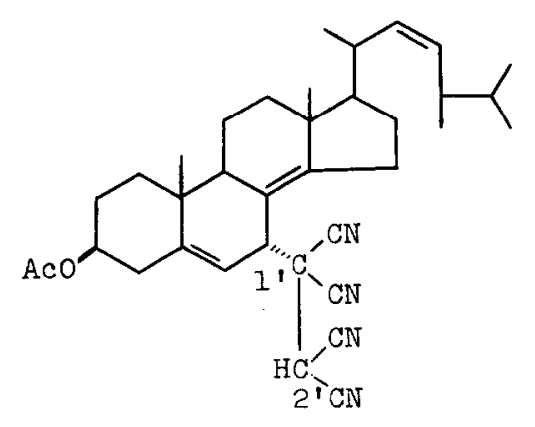

(IV)<smiles>COC(=O)N[C@@H]1C=C2CC(OC(C)=O)CCC2(C)C2=C1C1=CCC3(C)C2=C1CCC3C(C)/C=C\CC(C)C</smiles>

(VI)

(VII) 
$7 \alpha$-orientation is in accord with attack by tetracyanoethylene from the lesshindered $\alpha$-face of the steroid, with abstraction of the allylic I4a-hydrogen. The C-3 acetate methyl signal fell at $\tau 7.98$, and the C-18 and C-19 methyl signals coincided at $\tau$ 9.05. Coincidence of these signals has been observed with the other $7 \alpha$-substituted 5,8(14)-dienes [e.g. (I) and (II)], ${ }^{I}$ and is in accord with calculations from tables. 3 This observation reinforces our assignment of an $8(14)$ - rather than an $8(9)$-double bond, made above from the $u$.v. spectrum.

9(11)-Dehydroergosteryl acetate reacted rapidly at $5^{\circ}$ with tetracyanoethylene in benzene $\left(\mathrm{N}_{2}\right.$ atmosphere). The main product (29\% yield), $\mathrm{C}_{36} \mathrm{H}_{44}-$ $\mathrm{N}_{4} \mathrm{O}_{2}, \mathrm{~m} . \mathrm{p} \cdot 125-126^{\circ},[\alpha]_{\mathrm{D}}^{25}-99^{\circ}\left(\mathrm{CHCl}_{3}\right)$, is assigned the structure (V). The u.v. spectrum $\left[\lambda_{\max }^{\text {cyclohexane }} 280 \mathrm{m \mu}(\varepsilon 6550)\right]$ is consistent with a ring-C homoannular diene chromophore. ${ }^{4,5}$ In the n.m.r. spectrum the signal furthest down field was a l-proton multiplet at $\tau 4.39$ assigned to the C-ll proton. The C-6 proton gave a doublet at $\tau 4.68(\mathrm{~J}=2.5 \mathrm{c} . / \mathrm{sec}$ ) and the two side-chain vinyl protons a multiplet at $\tau 4.8 \%$. The $\mathrm{C}-3$ hydrogen gave a broad multiplet at ca. $\tau 5.41$, and superimposed on this was a sharp singlet at $\tau 5.33$, arising from the $\mathrm{C}-2^{\prime}$ proton. The $\mathrm{C}-7$ proton gave a doublet at $\tau 6.33(\mathrm{~J}=2.5 \mathrm{c} . / \mathrm{sec}$.$) ,$ clearly showing its coupling with the c-6 proton. The $\mathrm{C}-3$ acetate methyl signal fell at $\tau 7.99$ and the $c-18$ and $C-19$ methyl signals at $\tau 9.17$ and $\tau 8.73$ respectively. These latter values are consistent with those recorded ( $\tau 9.18$ and $\tau$ 8.80) for the similar compound (VI). 5 The tetracyanoethyl group is assigned the $7 \alpha$-configuration for analogous reasons to those given for (IV). These reactions appear to be the first ene-reactions involving tetracyanoethylene.

In marked contrast, ergosterol-B $B_{3}$ benzoate (3B-benzoyloxyergosta-7,14, 22triene) gave with tetracyanoethylene a Diels-Alder adduct $\mathrm{C}_{41} \mathrm{H}_{48} \mathrm{~N}_{4} \mathrm{O}_{2}, \mathrm{~m}$. p. $212-$ $213^{\circ},[\alpha]_{D}^{25}-93^{\circ}\left(\mathrm{CHCl}_{3}\right)$, in $86 \%$ yield. The n.m.r. spectrum of this adduct below $\tau 7.7$ showed only phenyl protons ( $\tau 2.3$ b side-chain vinyl protons ( $\tau 4.75$ ), and the $6-3$ proton $(\tau$ 5.2), clearly showing that a Diels-Alder rather than an ene-reaction had taken place. The structure (VII)* is suggested for this compound. The expected $8(14)$-, rather than an 8(9)-location for the nuclear double bond, although not unequivocally evident from the $u . v$. spectrum is supported by analogy *Models suggest a preferred "rear attack" of the dienophile. 
with exgosteryl- $\mathbb{H}_{3}$ acetate-maleic anhydride adduct. ${ }^{2}$

In ergosterol-B $B_{3}$, the diene group is sterically accessible to the bulky dienophile, enabling Diels-Alder reaction to take place, while in ergosterol and $9(11$ )-dehydroergosterol models indicate that formation of the required "benzenoid" transition state is subject to severe steric hindrance. In these cases, ene-reactions involving the $7(8)$-double bond and the $14 \alpha$-hydrogen take place to the exclusion of the Diels-Alder reaction. Further work in this area is in progress.

Acknowledgment. This work was supported in part by Institutional Research Grant No. IN-4OH to The University of Michigan from the American Cancer Society, to whom we express our thanks.

\section{References}

1. D. N. Jones, P. F. Greenhalgh, and I. Thomas, Tetrahedron, 24, 5215 (1968).

2. P. Bladon, H. B. Henbest, and G. W. Wood, I. Chem. Soc., 2737 (1952).

3. N. S. Bhacea and D. H. Williams, "Applications of N.M.R. Spectroscopy in Organic Chemistry," Holden-Day, San Francisco, 1964, pp. 19 et seq.

4. L. F. Fieser and M. Fieser, "Steroids", Reinhold Publishing Corp., New York, 1959, p. 18.

5. A. van der Gen, W. A. Zunnebeld, U. K. Pandit, and H. O. Huisman, Tetrahedron, 21, 3651 (1965). 